\title{
Biomass Evolution in Porous Media and Its Effects on Permeability Under Starvation Conditions
}

\author{
Dong-Shik Kim, H. Scott Fogler \\ Department of Chemical Engineering, University of Michigan, The Herbert \\ H. Dow Building, 2300 Hayward Street, Ann Arbor, Michigan 48109, USA; \\ telephone: (734)-763-1361; fax: (734)-763-0459; e-mail: sfogler@umich.edu
}

Received 8 August 1999; accepted 29 January 2000

\begin{abstract}
The purpose of this study was to understand bacteria profile modification and its applications in subsurface biological operations such as biobarrier formation, in situ bioremediation, and microbial-enhanced oil recovery. Biomass accumulation and evolution in porous media were investigated both experimentally and theoretically. To study both nutrient-rich and carbon-sourcedepleted conditions, Leuconostoc mesenteroides was chosen because of its rapid growth rate and exopolymer production rate. Porous micromodels were used to study the effects of biomass evolution on the permeability of a porous medium. Bacterial starvation was initiated by switching the feed from a nutrient solution to a buffer solution in order to examine biofilm stability under nutrient-poor conditions. Four different evolution patterns were identified during the nutrient-rich and nutrientdepleted conditions used in the micromodel experiments. In phase I, the permeability of the porous micromodel decreased as a result of biomass accumulation in pore bodies and pore throats. In phase II, starvation conditions were initiated. The depletion of nutrient in the phase II resulted in slower growth of the biofilm causing the permeability to reach a minimum as all the remaining nutrients were consumed. In phase III, permeability began to increase due to biofilm sloughing caused by shear stress. In phase IV, shear stress remained below the critical shear stress for sloughing and the biofilm remained stable for long periods of time during starvation. The critical shear stress for biofilm sloughing provided an indication of biofilm strength. Shear removal of biofilms occurred when shear stress exceeded critical shear stress. A network model was used to describe the biofilm formation phenomenon and the existence of a critical shear stress. Simulations were in qualitative agreement with the experimental results, and demonstrate the existence of a critical shear stress. (C) 2000 John Wiley \& Sons, Inc. Biotechnol Bioeng 69: 47-56, 2000.
\end{abstract}

Keywords: biofilm; Leuconostoc mesenteroides; exopolymer; network model; permeability; micromodel

\section{INTRODUCTION}

Biomass accumulation and evolution affect the performance of subsurface biological operations, such as in situ bioremediation (Rittman, 1994) and microbial-enhanced oil re-

Correspondence to: H. S. Fogler covery (MEOR) (Donaldson, 1991). Biomass accumulation on solid surfaces in porous media leads to biofilm formation, which can cause a decrease in permeability of the media (Lappan and Fogler, 1996). This permeability decrease affects the biological activity by changing nutrient flow pathways and bacterial transport (Cunningham et al., 1991; Peyton, 1996; Vandevivere and Baveye, 1992). It is necessary, therefore, to understand the mechanisms of biomass accumulation and evolution of flow pathways to better control nutrient loading rates and bacterial transport in porous media.

A biofilm is composed of a network of extracellular polymers (exopolymers) and embedded cells. In the presence of the proper nutrient, cells within a biofilm can undergo replication and produce biopolymers (or exopolymers), both of which result in expansion of the biofilm (Bryers, 1984; Dols et al., 1999). As the biofilm expands due to cell growth and biopolymer production, it spreads on the surface and its thickness increases. In a flow system, however, biofilms are susceptible to sloughing (biofilm detachment) as a result of the shear stress applied by the fluid flowing over the biofilm. Studies on biofilm sloughing have found that it is affected by the thickness, density, and strength of the biofilm (Bakke et al., 1984; Kreikenbohm and Stephen, 1985; Rittmann, 1982). The strength of the biofilm can change, as exopolymer gels are formed due to the hydration and crosslinking of biopolymer chains. The calculated critical shear stress was used as an indication of the strength of biofilm strength under conditions in which the bacteria in the micromodel were starved.

Although most biofilm research has been conducted under nutrient-rich conditions, studies on biofilm evolution without cell growth under nutrient-poor conditions are rare (Tan et al., 1994; Taylor and Jaffé, 1990). Biofilms in the subsurface often experience nutrient-poor conditions not only because of economic considerations for nutrient termination, but also due to constriction in the flow path of nutrient solution. Consequently, a fundamental understanding of the effects of bacterial starvation on biofilm evolution is required.

In this study, biofilm evolution was investigated under 
bacterial starvation conditions. Leuconostoc mesenteroides NRRL B-523 was used for this study because of its rapid growth and ability to form exopolymers, and also because of its potential applications to subsurface operations, such as microbial-enhanced oil recovery (Xiu-Yuan and Wang, 1991). The permeability of the porous media decreased as a result of biomass accumulation during nutrient injection. The results are reported in terms of the permeability ratio, $K / K_{o}$, which is the ratio of the permeability at time $t$ to the initial permeability as a function of dimensionless time. The dimensionless time (pore volume injection, PV) used in this study is the product of time, $t$, and the flow rate through the system divided by the fluid volume in the system. When the permeability ratio decreased to a predetermined value, a phosphate-buffered saline solution was injected to initiate starvation. Biofilm evolution under nutrient-rich and -poor conditions were monitored in a porous micromodel. Changes in the permeability ratio and biofilm morphology during growth and starvation were used to describe the evolution of biofilms under bacterial starvation conditions.

\section{MATERIALS AND METHODS}

Micromodels were used to determine how the biofilm affects permeability under nutrient-poor conditions. The inoculant cells for these experiments were grown in a growth medium overnight, and then concentrated by centrifuge $\left(5500 \mathrm{~g}\right.$ for $15 \mathrm{~min}$ at $\left.4^{\circ} \mathrm{C}\right)$. The growth medium was a phosphate-buffered saline solution with yeast extract (11.1 $\left.\mathrm{g} / \mathrm{dm}^{3}\right), \mathrm{NaCl}(0.07 M), \mathrm{NH}_{2} \mathrm{Cl}(0.06 M), \mathrm{CH}_{3} \mathrm{COONa}(0.06$ $M)$, ascorbic acid $\left(0.5 \mathrm{~g} / \mathrm{dm}^{3}\right)$, trace minerals, and the carbon source (a combination of glucose and fructose, $0.1 \mathrm{M}$ ). The combination of glucose and fructose can maintain cell growth without inducing the production of exopolymers. The trace minerals were prepared by individually dissolving $\mathrm{MgSO}_{4} \cdot 7 \mathrm{H}_{2} \mathrm{O}(12.3 \mathrm{~g} / \mathrm{mL}), \mathrm{FeSO}_{4} \cdot 7 \mathrm{H}_{2} \mathrm{O}(1.39 \mathrm{~g} / \mathrm{mL})$, and $\mathrm{MnSO}_{4}(0.85 \mathrm{~g} / \mathrm{mL})$ in D.I. water to make stock solutions. Each stock solution $(2 \mathrm{~mL})$ was added to $1 \mathrm{dm}^{3}$ of phosphate-buffered saline solution. The final concentration of trace minerals in both the growth and the starvation medium was $12.7 \mu M$ for $\mathrm{MnSO}_{4}, 10 \mu M$ for $\mathrm{FeSO}_{4} \cdot 7 \mathrm{H}_{2} \mathrm{O}$, and $100 \mu M$ for $\mathrm{MgSO}_{4} \cdot 7 \mathrm{H}_{2} \mathrm{O}$. For starvation, the same phosphate-buffered saline solution with the same concentrations of trace minerals was used for the growth medium but without carbon sources. The experiments were performed at $25^{\circ} \mathrm{C}$ in a laminar hood.

A micromodel was used to visualize the biofilm morphology and movement during cell injection, growth, and starvation in porous media (Fig. 1). The micromodel is formed by etching a mirror image on each of two glass plates, which are then fused together to create a two-dimensional network of flow channels that simulate porous media. Details of the micromodel production procedure can be found elsewhere (Chatenever and Calhoun, 1952; McKellar and Wardlaw, 1982). The net surface charge of the glass is negative and, if untreated, the surface is water-wet. The heterogeneous pattern was used for the network lattice in which the pore-

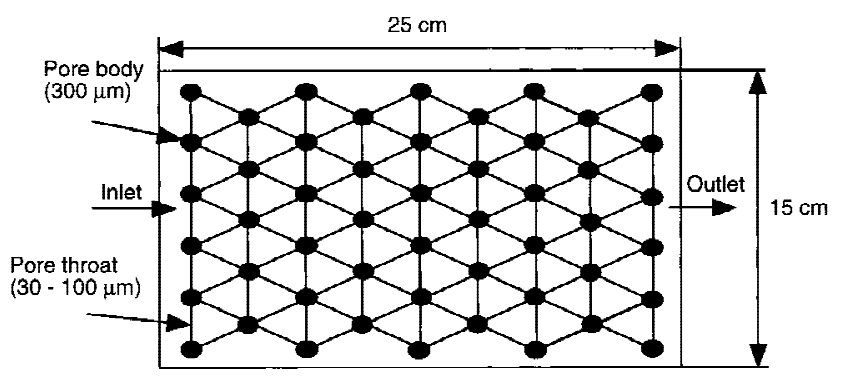

Figure 1. Schematic of micromodel with a triangular lattice pattern.

throat-size distribution generated using a random number generator ranged from 30 to $100 \mu \mathrm{m}$. The pore bodies were approximately $300 \mu \mathrm{m}$ in diameter. The random number generator assigns pore throat size based on a normal Gaussian distribution. Experimental measurements of mean and standard deviation of pore diameters in natural ceramic cores were used as a basis for the Gaussian distribution. The internal pore volume of the micromodel was measured to be $0.3 \mathrm{~mL}$.

The etched pattern used for the micromodel has a network of large pore spaces (pore bodies) connected by narrow constrictions (pore throats), as suggested by Wardlaw (1976). This idealization is based on the observation that the void space in natural porous media is an arrangement of converging and diverging channels with a distribution of sizes (Dullien and Dhawan, 1974). We used twodimensional triangular geometry (coordination number 6) for this study, as shown in Figure 1. This two-dimensional geometry has been used previously to study particle entrapment (Rege and Fogler, 1987) and carbonate acidizing (Hoefner and Fogler, 1988). The same geometry has been used for the network model, as described in the Discussion section, which can minimize the deviation between computer simulation (using network model) and experiments (using the micromodel).

The micromodel is connected to a syringe pump for fluid injection at a constant flow rate. A stereo-zoom microscope (Olympus SZ-CTV) connected to a CCD camera is placed over the micromodel to observe the biofilm in the pore space (Fig. 2). A VCR connected to the CCD camera was used to record the biofilm morphology and movement. The entire system was pressurized using nitrogen gas at 20 psig in order to prevent $\mathrm{CO}_{2}$ gas bubbles from forming during the fermentation. A differential pressure transducer was used to monitor the pressure drop across the micromodel. A schematic of the complete micromodel experimental system is shown in Figure 2.

The centrifuged inoculum was injected from the outlet line of the micromodel to avoid cell growth and blockage within the inlet line. When the inoculum reached the midpoint of the micromodel, all inlet and outlet lines were closed. After $1 \mathrm{~h}$, the inoculum was flushed out by injecting yeast extract solution at a flow rate of $0.5 \mathrm{~mL} / \mathrm{min}$ from the inlet to the outlet. Following inoculum flushing, a sucrose nutrient solution was injected at $0.02 \mathrm{~mL} / \mathrm{min}$ to grow cells 


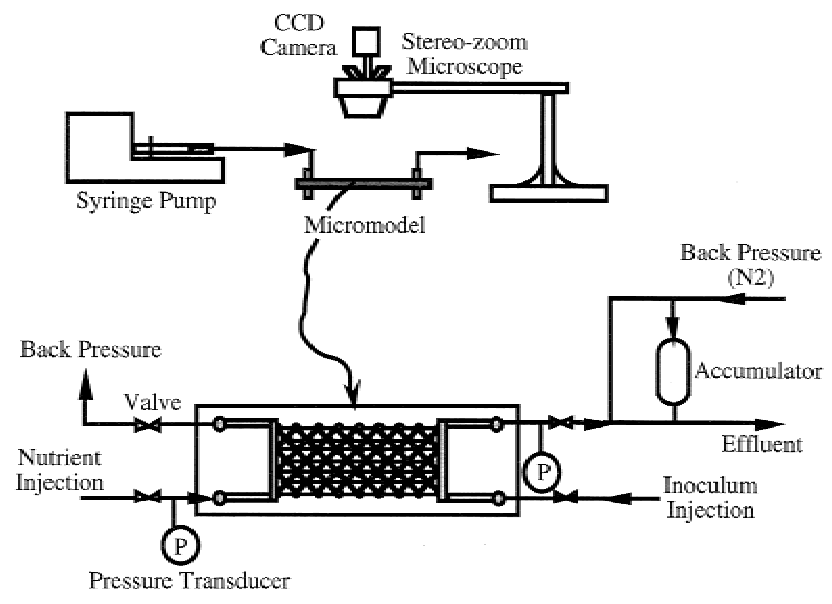

Figure 2. Schematic of the micromodel experimental system.

and produce exopolymers in the micromodel. When the permeability ratio was decreased to a predetermined value, namely $0.9,0.5,0.02$, or 0.01 , the nutrient was switched to buffer solution (no carbon sources) to initiate starvation.

\section{RESULTS AND DISCUSSION}

Sucrose induces L. mesenteroides NRRL B-523 (ATCC 14935) to produce dextransucrase, which decomposes sucrose into glucose and fructose. Dextransucrase also polymerizes glucose molecules into insoluble dextran by linking glucose through $75 \% \alpha-1,6-$ and $25 \% \alpha-1,3-$ and $\alpha-1,6-$ glucosidic bonds (Jeanes et al., 1954). Details of the growth kinetics and exopolymer production mechanism can be found elsewhere (Dols et al., 1999; Lappan and Fogler, 1994).

The permeability of porous media decreases as bacterial cells grow, and exopolymers are produced, thereby reducing and plugging the pore space. The changes in permeability were calculated using Darcy's law:

$$
Q=\frac{K}{\eta} \frac{\Delta P}{L} A
$$

Under the condition of constant flow rate, Eq. (1) can be used to determine the ratio of the permeability at any time $t$ to the initial permeability, $K / K_{o}$, from measured values of the pressure drop ratio, $\Delta P_{o} / \Delta P$ :

$$
\frac{K}{K_{o}}=\frac{\Delta P_{o}}{\Delta P}
$$

This ratio, $K / K_{o}$, was reported as a function of dimensionless time, which is the number of pore volumes (PV) of fluid passed through the micromodel.

The pressure drop across the micromodel and the biofilm morphology were monitored during both nutrient injection and starvation. The pressure drop was measured every minute throughout the entire experiment and converted to the permeability ratio using Eq. (2). The biofilm morphology observed in the micromodels demonstrated the biofilm accumulation during nutrient injection and biofilm stabilization during starvation.

The permeability ratio is a function of the properties of porous media (porosity, range of pore sizes, small maximum pore radius, surface properties, etc.) (Taylor and Jaffé, 1991). However, in this study, we focused on two important permeability ratios in the biomass evolution. The first is the permeability ratio at which starvation was initiated, and the second is the ratio at which no further changes in permeability occur (i.e., the final permeability ratio). The permeability ratio at any time $t, K / K_{o}$, is a function of the amount and integrity of the biofilm, which is in turn a function of the time the biofilm is supplied with nutrient. Figure 3 shows how the permeability ratio, $K / K_{o}$, changed during the injection of nutrient (cell growth and exopolymer production) and also during starvation. The effects of initiating starvation were tested for the following four pore volumes: 20 PV (5 h, exp. A); 60 PV (15 h, exp. B); 110 PV (28 h, exp. C); and 122 PV (31 h, exp. D). For the case of initiating starvation after only $20 \mathrm{PV}$, the biofilm did not have sufficient time to evolve and block the pore throats and bodies in order to change the permeability significantly. When starvation was initiated at the other PV, the evolution patterns of the permeability ratio were similar. Before initiating starvation by switching from the nutrient to the buffer solution, the permeability ratio decreased due to cell and exopolymer production generated from sucrose consumption. This production of biomass blocked the pore throats causing alternation in the flow pattern and a decrease in permeability. In this phase, biofilm sloughing is small in comparison with biofilm growth rate causing plugging. After the nutrient feed was switched to the buffer solution to initiate starvation, the permeability ratio continued to decrease as a result of bacterial growth from the remaining sucrose in the inlet line and in the micromodel pores. Once all the remaining nutrients were consumed, the permeability ratio reached a minimum value. The ratio of $K / K_{o}$ then began to increase as

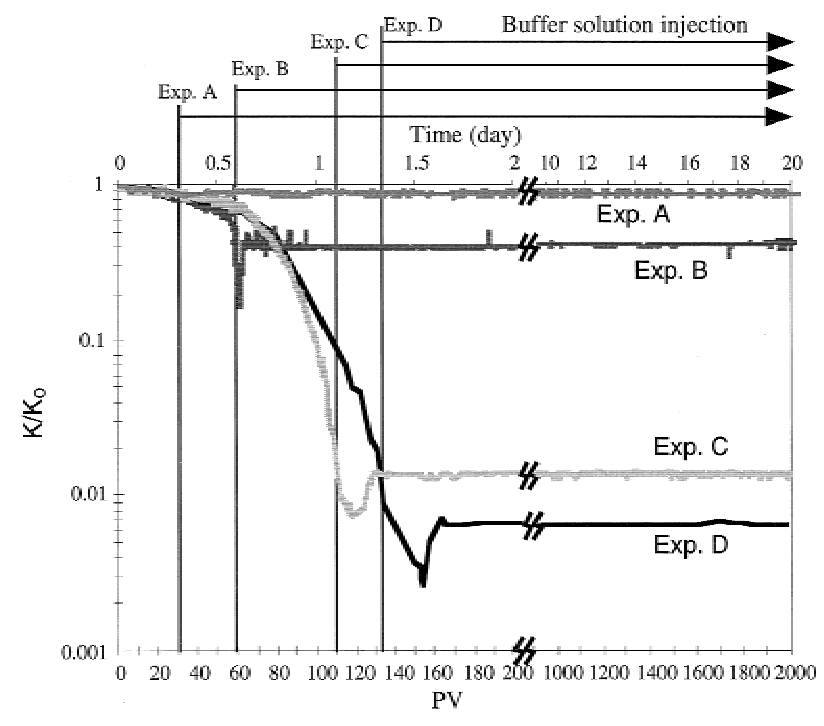

Figure 3. Comparison of $K / K_{o}$ for the different switching times. 
a result of removal of the biofilm by sloughing in the micromodel, thereby opening up some of the pore space for flow. After some sloughing the permeability ratio reached a value at which it remained constant throughout the rest of the experiment; that is, $\left(K / K_{o}\right)_{\text {final }}$.

Figures 4 and 5 show micromodel images for two conditions in switching to a buffer solution (i.e., starvation) when the permeability ratio, $K / K_{o}$, reached 0.5 , and another when the ratio reached 0.02 [i.e., $\left(K / K_{o}\right)_{\text {starve }}=0.02$ ]. For each of these experiments, the micromodel images showed no significant change during the buffer solution injection (20 days, or 1920 PV). From the enlarged image, the biofilm colonies were observed not only to be formed on the porethroat surfaces of the micromodel, but also to fill in pore bodies (Fig. 6). These biofilm colonies were distributed throughout the downstream half of the micromodel. No biofilm formation was observed in the upstream half of the micromodel.

Table I summarizes: (1) the number of pore volumes injected up to the point where starvation was initiated by switching from the nutrient to buffer solution; (2) the permeability ratio when starvation was initiated, $\left(K / K_{o}\right)_{\text {starve }}$; and (3) the final permeability ratio, $\left(K / K_{o}\right)_{\text {final }}$. The final permeability ratio decreased as the number of pore volumes of nutrient injection (PV) before switching increased due to time allowed to develop more biofilm in the pores.

From the general trends observed in each experiment, four phases were identified for the biomass evolution process during nutrient injection and starvation (Fig. 7). In phase I, the permeability decreases due to biomass accumulation in the pore bodies and pore throats. In this phase, the biomass accumulation rate is greater than the rate of biomass removal by shear (sloughing). In phase II, starvation conditions are initiated, and the permeability ratio continues to decrease because of continued growth of cells due to the nutrient already in situ. This depletion on in situ nutrient results in a slower biofilm growth. In phase III, all in situ nutrients have been consumed and there is no more biomass growth, and only biomass sloughing occurs. Consequently, after the nutrients are consumed, the permeability ratio in-

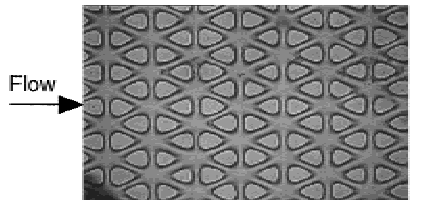

$\mathrm{PV}=10$ (3 hrs of sucrose injection)

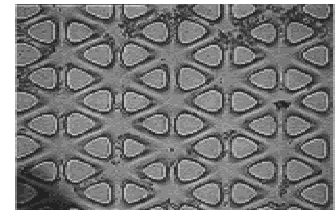

PV $=58$ (switched to buffer after $15 \mathrm{hrs}$ of sucrose injection)

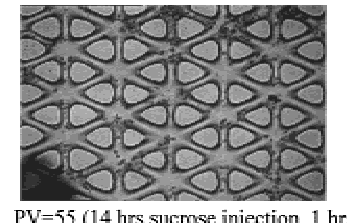

$\mathrm{PV}=55$ (14 hrs sucrose injection, $1 \mathrm{hrs}$ before buffer solution injection)

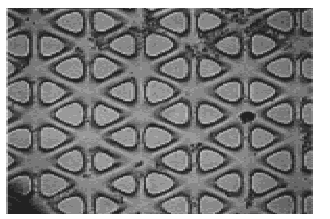

$\mathrm{PV}=1500$ ( 15 days of buffer solution injection)
Figure 4. Micromodel images of biofilm. Switching nutrient feed to buffer at $K / K_{o}=0.5$.

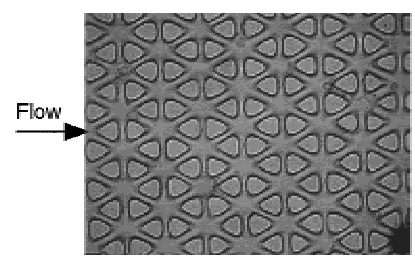

$\mathrm{PV}=12$ ( 3 hrs of sucrose injection)

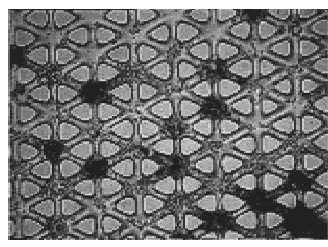

$\mathrm{PV}=120$ (1.3 days of sucrose injection, $2.5 \mathrm{hrs}$ before buffer injection)

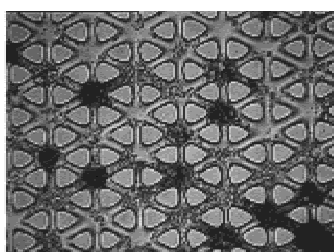

$\mathrm{PV}=150$ (5 hrs of buffer injection)
$\mathrm{PV}=80$ (20 hrs of sucrose injection)

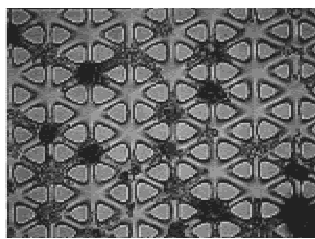

PV=130 (buffer solution injection)

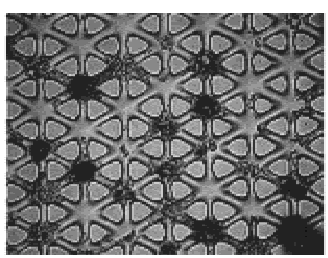

$\mathrm{PV}=1600$ (15 days of buffer injection)

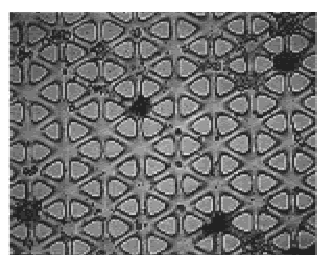

Figure 5. Micromodel images of biofilm. Switching nutrient feed to buffer at $K / K_{o}=0.02$.

creases in phase III due to biofilm shear removal, which partially opens the pore space, thereby reducing the shear stress on the biofilm. In phase IV, the permeability ratio levels off because sufficient pore space has been opened up so that the shear stress is no longer sufficient to remove any biomass from the pore space. The shear stress at which sloughing no longer occurs is defined as the critical shear stress and gives an indication of the strength of biofilm against shear. Therefore, when the shear stress is larger than the critical shear stress, biofilm is sheared off and as a result the permeability increases. Likewise, when the shear stress is smaller than the critical shear stress, the permeability remains constant in this phase.

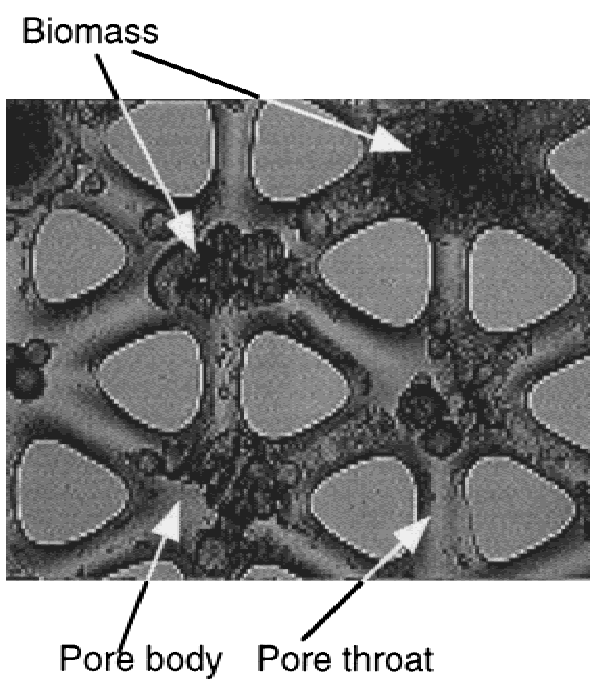

Figure 6. Biofilm growth in the pore space in micromodel. 
Table I. Experimental results with respect to nutrient switching time.

\begin{tabular}{ccc}
\hline $\begin{array}{c}\text { Ko } K_{o} \text { when nutrient } \\
\text { switched to } \\
\text { buffer, }\left(K / K_{o}\right)_{\text {starve }}\end{array}$ & $\begin{array}{c}\text { The number of } \\
\text { pore volumes } \\
\text { injected before } \\
\text { switching, }(\mathrm{PV})_{\text {starve }}\end{array}$ & $\begin{array}{c}\text { Final permeability } \\
\text { ratio, }\left(K / K_{o}\right)_{\text {final }}\end{array}$ \\
\hline 0.950 & 30 & 0.900 \\
0.480 & 63 & 0.410 \\
0.020 & 110 & 0.015 \\
0.009 & 131 & 0.0069 \\
\hline
\end{tabular}

The experiments were terminated because of two reasons. First, L. mesenteroides was sometimes transferred to the inlet flow line or the entrance area of the micromodel resulting in cell growth in these areas (inlet line contamination). In this case, the experiment must be terminated because the measured pressure drop no longer represents the biomass accumulation in the micromodel. The inlet line contamination was due to the long duration of the experiments, and the injection solution (nutrient, or buffer) had to be refilled periodically. During the refilling process, the syringe pump had to stop, and some cells diffused toward the inlet area. In some instances, a small pressure oscillation during the refilling process forced cells to move to the inlet area, resulting in the inlet line contamination. The second reason for termination of the experiment is based on evidence we obtained in batch experiments. No biopolymer degradation was observed in the patch experiments for a maximum 2 years (Kim and Fogler, 1999), which indicates that biopolymer accumulated in the micromodel is stable for a long period of time.

\section{Balance Equations}

Biofilm growth and removal was simulated using a network model that parallels the micromodel apparatus (Fatt, 1956; Hoefner and Fogler, 1988). The balance equations for cell,

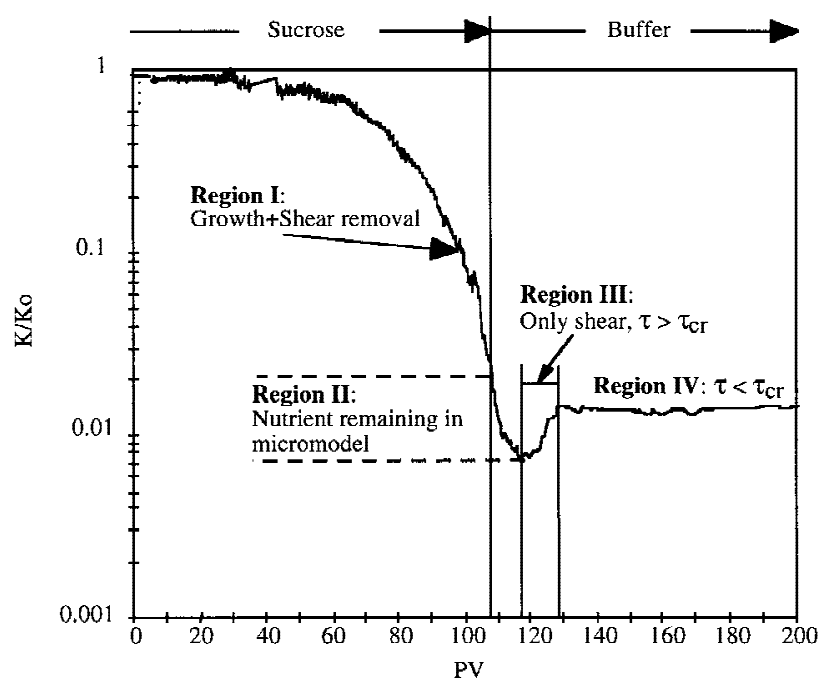

Figure 7. Effects of biofilm growth and shear stress on permeability ratio. $\sigma_{x}$, enzyme, $\sigma_{e}$, and exopolymer production, $\sigma_{i d}$, in the biofilm for each pore bond are given as follows:

Cells:

$$
\frac{\partial \sigma_{x}}{\partial t}=r_{\text {enzyme production }}-r_{\text {sloughing }}
$$

Enzymes:

$$
\frac{\partial \sigma_{e}}{\partial t}=r_{\text {enzyme production }}-r_{\text {sloughing }}
$$

Insoluble polymer: $\quad \frac{\partial \sigma_{i d}}{\partial t}=r_{\text {dextran production }}-r_{\text {sloughing }}$

Sucrose in biofilm: $\quad \frac{\partial C_{s i}}{\partial t}=r_{\text {sucrose consumption }}$

$$
+r_{\text {sucrose transport }}
$$

Sucrose in bulk phase: $\frac{\partial C_{s}}{\partial t}+U_{s} \frac{\partial C_{s}}{\partial z}=-r_{\text {sucrose transport }}$

$$
r_{\text {sucrose transport }}=k^{\prime} a\left(C_{s}-C_{s i}\right)
$$

The product, $k^{\prime} a$, in Eq. (8), combines the mass transfer coefficient, $k^{\prime}$, and the mass transfer flux area, $a$, and was estimated to be $12.5( \pm 1.5) \mathrm{h}^{-1}$ by Lappan and Fogler (1996).

\section{Rate Laws}

An in situ growth model (Lappan and Fogler, 1994) was used for cell growth and exopolymer production. Cell maintenance is neglected in this model:

$$
\begin{aligned}
r_{\text {cell production }} & =\mu^{\prime} \sigma_{x} \\
r_{\text {enzyme production }} & =k_{f} \sigma_{x} \\
r_{\text {polymer production }} & =Y_{i d} V_{\max _{d}}\left(\frac{C_{s}}{K_{d}+C_{s}}\right) \\
r_{\text {sucrose consumption }} & =-\left(V_{\max _{d}}+V_{\max _{g}}\right)\left(\frac{C_{s}}{K_{d}+C_{s}}\right)
\end{aligned}
$$

where:

$$
\begin{aligned}
\mu & =\mu_{\max }\left(\frac{C_{y e}}{K_{y e}+C_{y e}}\right)\left(\frac{\alpha C_{y e}+C_{s}}{K_{s}+\alpha C_{y e}+C_{s}}\right)\left(1-\frac{\sigma_{x}}{\sigma_{x_{\max }}}\right) \\
V_{\max _{d}} & =\theta_{d} \frac{k_{d}}{k_{f}} \sigma_{e} \\
V_{\max _{g}} & =\theta_{g} \frac{k_{g}}{k_{f}} \sigma_{e}
\end{aligned}
$$

The parameter values used in the rate laws are summarized in Table II. 


\section{Sloughing}

The first-order biofilm detachment expression given by Rittmann (1982) was used for shear removal:

$$
r_{\text {sloughing }}=\frac{d B_{\text {sloughing }}}{d t}=\beta \rho L_{f}=\beta \rho\left(r_{o}-r\right)
$$

where $B_{\text {sloughing }}$ is the weight of biomass sloughing. The detachment rate coefficient, $\beta$, was determined from a leastsquares analysis to be $\beta=0.16 \mathrm{~h}^{-1}$ with an $R^{2}$ value of 0.83 . The rate of biomass sloughing in each pore bond is greater than zero only when the shear stress on the biofilm is greater than the critical shear stress:

$$
\begin{array}{ll}
r_{\text {sloughing }}=0, & \tau<\tau_{\text {critical }} \\
r_{\text {sloughing }}>0, & \tau>\tau_{\text {critical }}
\end{array}
$$

\section{Permeability Ratio}

The last component of the model is to determine the permeability ratio as a function of time. This relationship can be developed by relating the changes in pressure drop caused by biomass buildup in the pore throats using the Hagen-Poiseuille equation:

$$
Q_{i j}=\frac{\pi}{8} \frac{r_{i j}^{4}}{\eta l} \Delta P_{i j}
$$

with a mass balance for pore body, $i$ :

$$
\sum_{j=1}^{6} Q_{i j}=0
$$

where $Q_{i j}$ is the flow rate from node $i$ to node $j$ through a pore radius of $r_{i j} . P_{i}$ and $P_{j}$ are the pressure in pore bodies $i$ and $j$ (Fig. 8). Using the cell and biopolymer concentrations $\left(\sigma_{x}\right.$ and $\left.\sigma_{i d}\right)$ and the biofilm density, the volume of the biofilm was calculated as:

$$
V_{\text {biofilm }}=\left(\frac{\sigma_{x} m+\sigma_{i d}}{\rho}\right) \pi\left(r_{o}^{2}-r_{1}^{2}\right) l
$$

where $m$ represents the weight of a single cell estimated to be $5.2 \times 10^{-7} \mu \mathrm{g}$.

The biofilm volume described in Eq. (20) can be updated by calculating pore radius, $r_{2}$, using Eq. (21) and Eq. (22). The biofilm thickness, $L_{f}$, is calculated using Eqs. (22) and (23):

$$
\begin{aligned}
V_{\text {biofilm }} & =\pi\left(r_{0}^{2}-r_{2}^{2}\right) l \\
r_{2} & =\sqrt{r_{0}^{2}-\frac{V_{\text {biofilm }}}{\pi l}} \\
L_{f} & =r_{o}-r_{2}
\end{aligned}
$$

After the bond diameters are assigned, the pressure drop at each node is calculated for a constant inlet flow rate. The boundary conditions are such that the pressure in nodes on the inlet face are equal, the pressure at the nodes in the last column are all equal to zero, and the sides of the array use periodic boundary conditions. As illustrated in Figure 8, a mass balance for each node, Eqs. (19) and (18), provides a set of linear algebraic equations that can be solved simultaneously to give the pressure drop at each node, from which the pressure drop across the network can be calculated. For an $n \times n$ network, this approach results in $n^{2}$ linear algebraic equations, one for the pressure at each node. The solution of the equations yields the pressure drop at each node, and from this the flow rate can be calculated. The pressure drop, $\Delta P$, across the network is used for calculating the network permeability using Eq. (2). We now only need to determine the decrease in pore throat radius as a function of time.

\section{Model Algorithm}

The set of differential equations describing biofilm growth and evolution, Eqs. (3)-(23), was solved using the Livermore Solver for Ordinary Differential Equations (LSODE) software package for each pore bond in the network model with periodic boundary conditions assigned to the sides of the network array. The partial differential equations were spatially discretized to reduce them to ordinary differential equations using the Method of Lines technique (Schiesser, 1991). The inlet sucrose and yeast extract concentrations were $15 \mathrm{~g} / \mathrm{dm}^{3}$ and $10 \mathrm{~g} / \mathrm{dm}^{3}$ at a constant flow rate 0.02 $\mathrm{mL} / \mathrm{min}$. Biomass sloughing (i.e., biofilm detachment) is considered to affect permeability. Eq. (16) was used to describe biofilm sloughing in the simulation. The parameter values used in simulation are given in Table II.

Figure 9 illustrates the biofilm evolution model for a pore bond with an initial radius of $r_{o}$. For each time step, the concentrations of cells and biopolymer were updated, and a new biofilm thickness was calculated using the concentrations of cells and biopolymer and the biofilm density. The biofilm density, $\rho$, was estimated as $92( \pm 4.6) \mathrm{g} / \mathrm{dm}^{3}$ by measuring the weight and volume of solid biomass after centrifuging a biomass suspension from a batch reactor for $15 \mathrm{~min}$ at $4000 \mathrm{~g}$. From the solution to Eqs. (3)-(15), we can
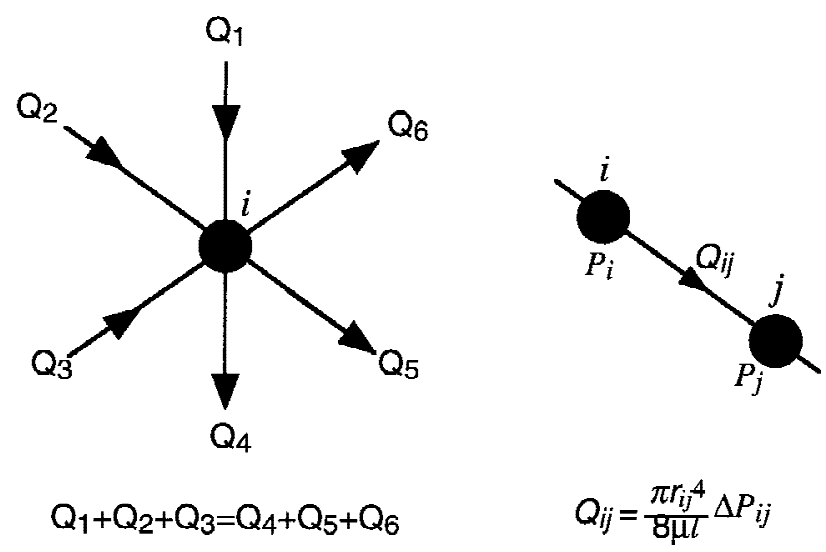

Figure 8. Flow-through pore throats into and out of a pore body. 
Table II. Parameter values used in simulation.

\begin{tabular}{ll}
\hline$C_{x \max }$ & $4.2 \times 10^{11} \mathrm{cells} / \mathrm{dm}^{3 \mathrm{a}}$ \\
$K_{y e}$ & $0.3 \mathrm{~g} \mathrm{yeast} \mathrm{extract/dm}^{3 \mathrm{~b}}$ \\
$k^{\prime} a$ & $12.5( \pm 1.5) \mathrm{h}^{-1 \mathrm{~b}}$ \\
$k_{1}$ & $1.48 \times 10^{-4} \mathrm{~h}^{-1 \mathrm{~b}}$ \\
$k_{d}$ & $13.7 \mathrm{pU} \mathrm{cell}{ }^{-1} \mathrm{~h}^{-1 \mathrm{~b}}$ \\
$k_{f}$ & $97.8 \mathrm{pU} \mathrm{cell}{ }^{-1} \mathrm{~h}^{-1 \mathrm{~b}}$ \\
$k_{g}$ & $84.1 \mathrm{pU} \mathrm{cell}{ }^{-1} \mathrm{~h}^{-1 \mathrm{~b}}$ \\
$k_{s}$ & $0.16 \mathrm{~h}^{-1 \mathrm{~b}}$ \\
$\rho$ & $92( \pm 4.6) \mathrm{g} / \mathrm{dm}^{3 \mathrm{c}}$ \\
$Y_{i d}$ & $0.24^{\mathrm{b}}$ \\
$\alpha$ & $0.5 \mathrm{~g} \mathrm{sucrose} / \mathrm{g} \mathrm{yeast} \mathrm{extract}^{\mathrm{b}}$ \\
$\theta_{d}$ & $0.07 \mathrm{~g} \mathrm{sucrose}^{-1} \mathrm{~h}^{-1 \mathrm{~b}}$ \\
$\theta_{g}$ & $1.23 \mathrm{~g}$ sucrose $\mathrm{U}^{-1} \mathrm{~h}^{-1 \mathrm{~b}}$ \\
\hline
\end{tabular}

${ }^{a}$ Measured value in batch experiments (Lappan and Fogler, 1994).

${ }^{\mathrm{b}}$ Estimated using batch experimental data (Lappan and Fogler, 1994).

${ }^{\mathrm{c}}$ Measured in batch experiments by the authors.

obtain the concentration of the cells $\left(\sigma_{x}\right.$ cells $\left./ \mathrm{dm}^{3}\right)$ and exopolymer $\left(\sigma_{i d} \mathrm{~g} / \mathrm{dm}^{3}\right)$ in biofilm as a function of time. This increase in concentration can be related to the decrease in pore radius (and permeability) using Eqs. (20)-(23). For each time step, it was assumed that the bond is an essentially cylindrical reactor with a sucrose concentration equal to that of its originating pore body. Because diffusional effects of sucrose are neglected, sucrose availability was also assumed to be constant for all biofilm layers. After the new biofilm thickness, $L_{f}$ was calculated for each pore radius, $r_{i j}$, biofilm sloughing resulting from shear in the pore was calculated using Eq. (16). The shear stress in each pore bond can be calculated using Eqs. (21) and (22) for the pore space diameter, $r_{2}$, as shown in Figure 9 (Bird et al., 1960):

$$
\tau=\left(\frac{\Delta P}{2 l}\right) r_{2}
$$

Because of this shear stress, biofilm is sheared off when $\tau$ is greater than the critical shear stress. The weight of biomass sloughing, $B_{\text {sloughing }}\left(\mathrm{g} / \mathrm{dm}^{2}\right)$, is calculated using Eq. (16). Therefore, the volume of biomass detached, $V_{\text {det }}$, and a new radius after sloughing, $r_{3}$, can be calculated (Fig. 9):

$$
V_{\text {det }}=\frac{2 B_{\text {sloughing }} \pi r_{2} l}{\rho}=\pi l\left(r_{3}^{2}-r_{2}^{2}\right)
$$

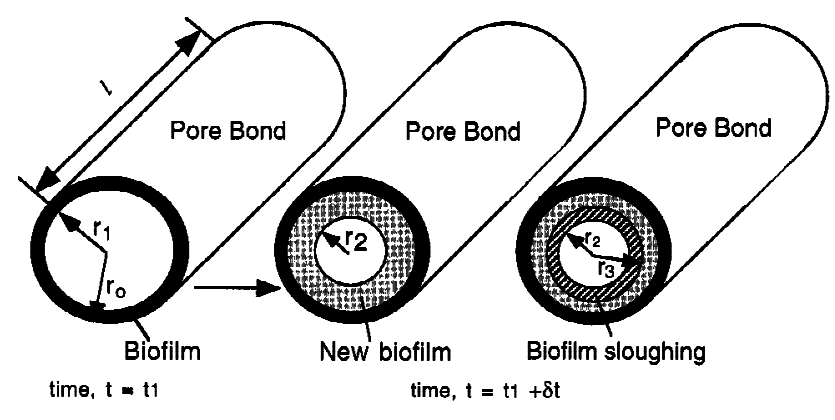

Figure 9. Biofilm evolution model in pore bonds.

$$
r_{3}=\sqrt{r_{2}^{2}+\frac{V_{\mathrm{det}}}{\pi l}}
$$

The new radius after sloughing, $r_{3}$, was used to update the permeability ratio, and was used for the next time step.

For each time step during starvation, the shear stress in each pore bond was calculated, and compared with the critical shear stress. If the shear stress was greater than the critical shear stress, the biofilm sloughing was calculated from Eq. (16) (i.e., $r_{2}$ increased), whereas no biofilm sloughing occurred (i.e., no change in $r_{2}$ ) when the shear stress was smaller than the critical shear stress. The critical shear stress was determined by varying the final permeability ratio, $\left(K / K_{\mathrm{o}}\right)_{\text {final }}$, in the simulation to match the experimental results. The calculated critical shear stresses are given in Table III.

To simulate the cell growth and biofilm accumulation using an in situ growth model in a network model, the initial biofilm thickness and the initial cell concentration in the biofilm needed to be specified. During the inoculation phase in the micromodel experiments, centrifuged cells were injected into the micromodel and remained shut in for $1 \mathrm{~h}$ before being flushed out with the yeast extract solution. The concentration of the centrifuged cells $\left(C_{x}\right)$ were measured as $1.2 \times 10^{11}\left( \pm 6.3 \times 10^{10}\right)$ cells $/ \mathrm{dm}^{3}$ using a Coulter counter. The cell concentration deposited on the surface was calculated using the rate equation for cell transport from bulk phase to solid surface:

$$
\frac{\partial \sigma_{x}}{\partial t}=-k_{1} C_{x}
$$

Eq. (27) neglects cell growth during inoculation, and $C_{x}$ was assumed to be constant during inoculation. The cell transport coefficient, $k_{1}$, was estimated to be $1.48 \times 10^{-4} \mathrm{~h}^{-1}$ (Lappan and Fogler, 1996). The concentration of deposited cells after $1 \mathrm{~h}$ was calculated as $8.16 \times 10^{7}$ cells $/ \mathrm{dm}^{3}$ from Eq. (27). This deposited cell concentration in the inoculation phase was used as an initial cell concentration for in situ growth simulation. The measured concentration of initially deposited cells had a relatively wide range of error due to fast cell growth during the inoculation and the difficulties in measuring a small number of deposited cells compared with the large bulk cell concentration. The estimated initial cell deposition fell into the measured range of concentration.

\section{Simulation Results}

The simulation results for the case of starvation when $K / K_{o}$ reached $0.02,\left(K / K_{o}\right)_{\text {starve }}=0.02$, are shown, along with

Table III. Critical shear stress with respect to the final permeability ratio.

\begin{tabular}{cc}
\hline$\left(K / K_{o}\right)_{\text {final }}$ & $\begin{array}{c}\text { Critical shear stress, } \\
\tau_{\text {critical }}(\mathrm{Pa})\end{array}$ \\
\hline 0.900 & $4.70 \times 10^{2}$ \\
0.410 & $1.25 \times 10^{3}$ \\
0.015 & $7.84 \times 10^{4}$ \\
0.007 & $2.03 \times 10^{5}$ \\
\hline
\end{tabular}


experimental data, in Figure 10. Although the simulation results represented the decrease of permeability ratio during nutrient injection, it did not demonstrate a constant final permeability ratio, $\left(K / K_{o}\right)_{\text {final }}$, as was observed in the experiments. Instead, the permeability ratio increased continuously, but at a slow rate. To incorporate the resistance of the biofilm to shear stress during starvation, the critical shear stress was used in the starvation simulation. By incorporating the average critical shear stress, the simulation results are consistent with the experimental data (Fig. 11). The average pore velocity at critical shear stress was estimated for each data set using the $\left(K / K_{o}\right)_{\text {final }}: 3.63 \times 10^{-5}$ for exp. A; $5.38 \times 10^{-5}$ for exp. B; $2.81 \times 10^{-4}$ for exp. C; and 4.12 $\times 10^{-4}$ for exp. D.

An increase in critical shear stress with nutrient injection was observed in the micromodel experiments. This result indicates that biofilm becomes more resistant to sloughing when a longer pulse of nutrient is applied before initiating starvation. As can be seen in Figure 12, the biofilm in the micromodel is an aggregation of cells embedded in a gel matrix. The biofilm becomes more resistant to shear stress as the gelation of exopolymers occurs (Christensen and Characklis, 1990). As the nutrient feed continues, the biofilm near the surface wall (base film) becomes denser than the biofilm near the liquid interface. An increase in biofilm density with biofilm depth was also reported by Christensen and Characklis (1990). In their study the biofilm density of the base film (biofilm close to solid surface) was approximately three times larger than that of surface film (biofilm close to liquid layer). This density difference between base film and surface film means that newly produced biofilm at the liquid interface is less dense than the base film. Therefore, the surface film is more susceptible to shear stress because of the low density of the biofilm and insufficient gelation. This lower density of surface film explains the permeability evolution observed in the micromodel experiments. As shown in Figure 3, the permeability ratio

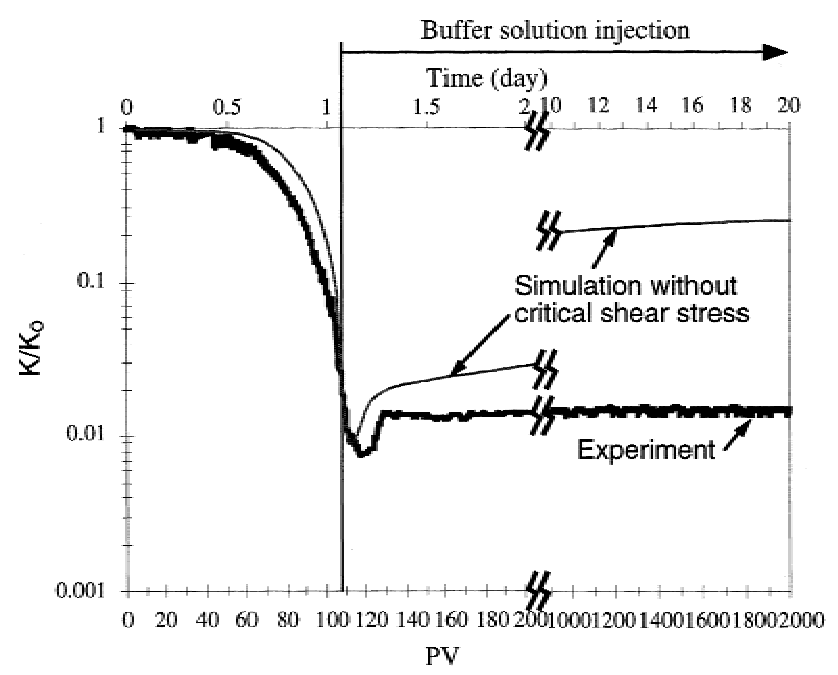

Figure 10. Comparison of experimental and simulation data without using critical shear stress.

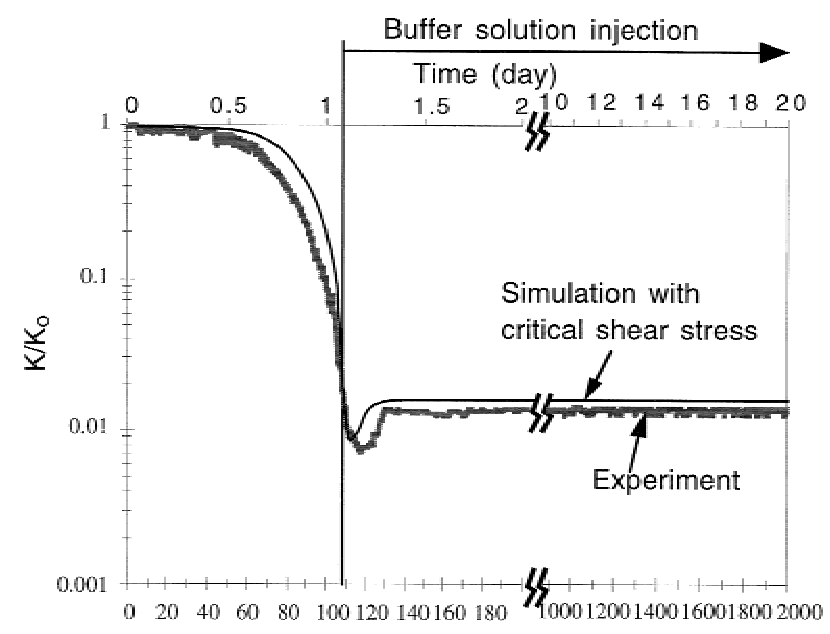

PV

Figure 11. Comparison of experimental data and simulation results using critical shear stress.

$\left(K / K_{o}\right)$ continued to decrease even after the nutrient was switched to buffer solution, and then, after reaching the minimum, it increased until it leveled off. This evolution pattern of the permeability ratio indicates that the biofilm formed after switching the nutrient (newly produced biofilm) did not have sufficiently strong binding, and was sheared off easily. The sloughing of surface film results in a final permeability ratio, $\left(K / K_{o}\right)_{\text {final }}$, close to that when the nutrient was switched and starvation initiated, $\left(K / K_{o}\right)_{\text {starve }}$.

Figure 13 shows the network representation of biofilm evolution generated by the computer simulation. These structures are in qualitative agreement with the micromodel images obtained experimentally (Figs. 4 and 5). In the mi-

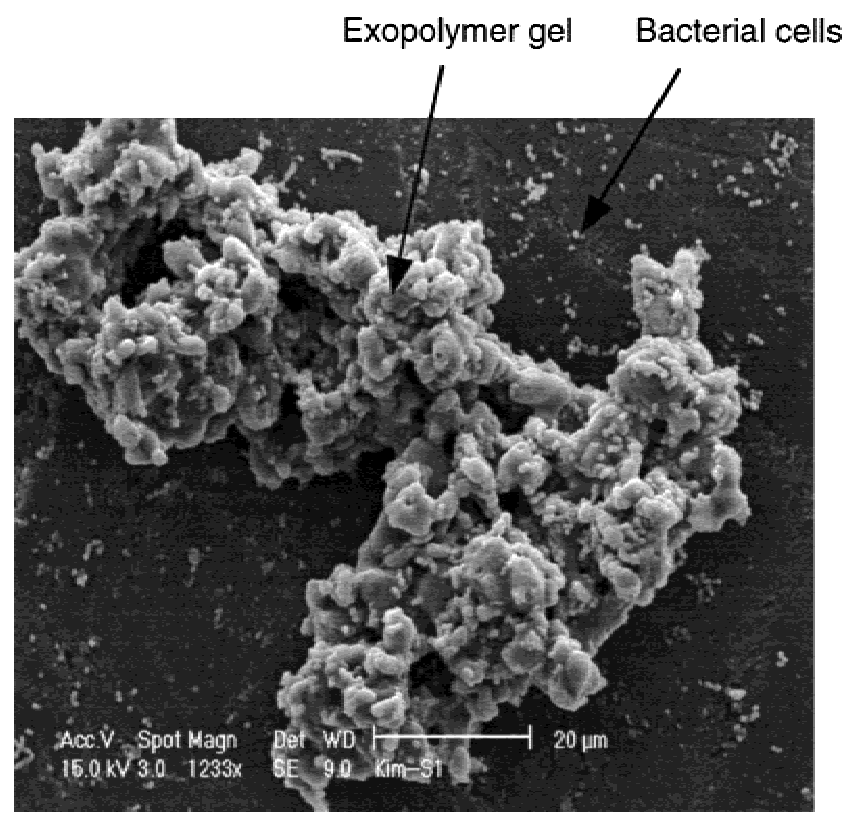

Figure 12. SEM picture of exopolymer gel and bacterial cells growing on a solid surface. 


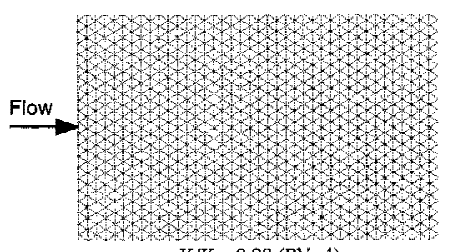

$\mathrm{K} / \mathrm{K}_{0}=0.98(\mathrm{PV}=4)$

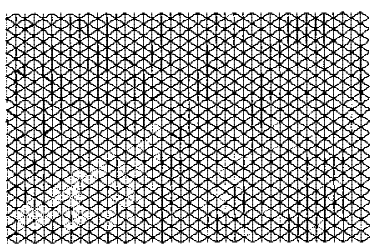

$\mathrm{K} / \mathrm{K}_{0}=0.5(\mathrm{PV}=81)$

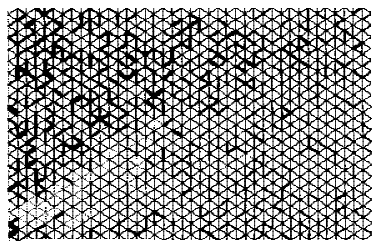

$\mathrm{K} / \mathrm{K}_{0}=0.01(\mathrm{PV}=113)$
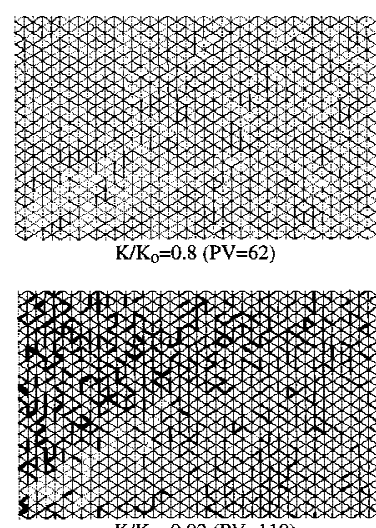

$\mathrm{K} / \mathrm{K}_{0}=0.02(\mathrm{PV}=110)$

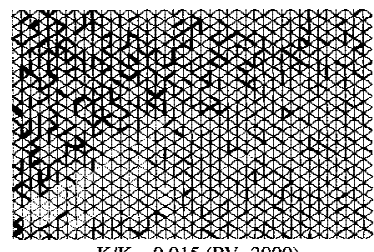

$\mathrm{K} / \mathrm{K}_{\mathrm{o}}=0.015(\mathrm{PV}=2000)$

Figure 13. Network representation of biomass evolution with critical shear.

cromodel experiments, the increase in biofilm mass causes the pore throats to become more constrictive as more biofilm accumulates. Likewise, pore bonds containing more biofilm in the network representation are indicated by thicker, darker lines. As shown in Figure 13, the pore bonds became thicker and darker during nutrient injection, and the bond structure showed no change after nutrient feeding switched to a buffer solution feeding, which corresponds to the constant final permeability ratios observed in the experiments.

\section{CONCLUSIONS}

Biomass accumulation and evolution under starvation conditions was investigated using micromodels and network model simulations. Four different evolution phases were observed and identified in the micromodel experiments. The experimentally observed decrease in permeability was a result of biomass accumulation in pore space (phase I). After termination of the nutrient feed to initiate the starvation conditions, the permeability ratio continued to decrease due to nutrients remaining in the system (phase II). However, after the remaining nutrients were consumed, the biomass formed during phase II was sheared off, resulting in an increase in some radii and in permeability (phase III). In phase IV, the permeability ratio leveled off because flow velocity was not large enough to shear off any more of the biofilm from the pore bonds.

Micromodel has demonstrated that it is a useful tool for observing biomass accumulation and evolution in porous media. Biomass was observed to accumulate mostly in the pore bodies, but as the nutrient feeding continued it accumulated in the pore throats. Visualization of biomass in

porous media using micromodels made it possible to study the mechanisms of biomass accumulation and movement during nutrient and buffer solution injection, and evolution of flow paths in porous media. It was also shown to be possible to place the concentrated inoculum in a desired area without contaminating the inlet line that eventually causes the inlet line plugging.

The critical shear stress provides an indication of biomass strength. As exopolymers in biomass become denser and form a gel, the biofilm resistance near the surface wall (base film) to shear stress becomes greater, resulting in greater critical shear stress.

A network model was used to simulate biomass evolution. Simulations using critical shear stress were found to be in excellent qualitative agreement with the experimental data obtained during starvation.

The biomass evolution pattern observed in the experiments, and the evolution model with critical shear stress, can be used for better control and prediction of the permeability of porous media under various nutrient conditions.

\section{NOMENCLATURE}

\begin{tabular}{|c|c|}
\hline$A$ & cross-sectional area of porous medium $\left(\mathrm{m}^{2}\right)$ \\
\hline$B_{\text {sloughing }}$ & weight of biomass sloughing $\left(\mathrm{g} / \mathrm{dm}^{2}\right)$ \\
\hline$C_{s}$ & bulk concentration of sucrose $\left(\mathrm{g} / \mathrm{dm}^{3}\right)$ \\
\hline$C_{s i}$ & $\begin{array}{l}\text { concentration of sucrose at the interface between liquid } \\
\text { layer and biofilm }\left(\mathrm{g} / \mathrm{dm}^{3}\right)\end{array}$ \\
\hline$C_{x}$ & concentration of cells in the inoculant $\left(\right.$ cells $\left./ \mathrm{dm}^{3}\right)$ \\
\hline$d$ & diameter of pore bond $(\mathrm{m})$ \\
\hline$K_{o}$ & initial micromodel permeability $\left(\mathrm{m}^{2}\right)$ \\
\hline$K_{d}$ & $\begin{array}{l}\text { Michaelis-Menten constant for sucrose utilization ( } \mathrm{g} / \\
\left.\mathrm{dm}^{3}\right)\end{array}$ \\
\hline$K_{s}$ & Monod constant for sucrose $\left(\mathrm{g} / \mathrm{dm}^{3}\right)$ \\
\hline$K_{y e}$ & Monod constant for yeast extract $\left(\mathrm{g} / \mathrm{dm}^{3}\right)$ \\
\hline$K / K_{o}$ & permeability ratio \\
\hline$k^{\prime} a$ & mass transfer coefficient flux area product $(\mathrm{h})$ \\
\hline$k_{i}$ & $\begin{array}{l}\text { activity of the enzyme per volume per cell to produce } \\
\text { product } i \text { (pU/cell per hour) }\end{array}$ \\
\hline$L$ & porous media length $(\mathrm{m})$ \\
\hline$L_{f}$ & biofilm thickness (m) \\
\hline$l$ & length of pore bond $(\mathrm{m})$ \\
\hline$m$ & weight of single cell $(\mathrm{g})$ \\
\hline$\Delta P$ & pressure drop $\left(\mathrm{N} / \mathrm{m}^{2}\right)$ \\
\hline$Q$ & flow rate $\left(\mathrm{m}^{3} / \mathrm{s}\right)$ \\
\hline$r$ & open-space diameter in pore bond $(\mathrm{m})$ \\
\hline$r_{d}$ & biofilm detachment rate $(\mathrm{g} / \mathrm{h})$ \\
\hline$r_{\text {sucrose transport }}$ & $\begin{array}{l}\text { rate of sucrose transport from bulk phase to biofilm } \\
\text { interface }\left(\mathrm{g} / \mathrm{dm}^{3} \text { per hour) }\right.\end{array}$ \\
\hline$r_{\text {cell transport }}$ & $\begin{array}{l}\text { rate of cell transport from bulk phase to solid surface } \\
\text { during inoculation phase (cells } / \mathrm{dm}^{3} \text { per hour) }\end{array}$ \\
\hline$t$ & time $(h)$ \\
\hline$U_{s}$ & average velocity in pore bond $(\mathrm{m} / \mathrm{h})$ \\
\hline$V_{\text {biofilm }}$ & volume of biofilm in pore bond $\left(\mathrm{dm}^{3}\right)$ \\
\hline$W_{b}$ & weight of biofilm $(\mathrm{g})$ \\
\hline$Y_{i}$ & cell yield from species $i$ consumption (cells/g) \\
\hline & length dimension $(\mathrm{m})$ \\
\hline
\end{tabular}

Greek letters

$\alpha \quad$ yeast extract conversion factor (g sucrose/g yeast extract)

$\beta \quad$ biofilm detachment rate coefficient $\left(\mathrm{h}^{-1}\right)$

$\mu \quad$ specific growth rate $\left(\mathrm{h}^{-1}\right)$ 
$\eta \quad$ viscosity of fluid $(\mathrm{kg} / \mathrm{m} \cdot \mathrm{s})$

$\theta_{i} \quad$ dimensionless reaction rate constant for sucrose consumption to produce product $i$ at reaction temperature ( $\mathrm{g} / \mathrm{U}$ per hour)

$\rho \quad$ biofilm density $\left(\mathrm{g} / \mathrm{dm}^{3}\right)$

$\sigma \quad$ concentration of species in biofilm $\left(\mathrm{g} / \mathrm{dm}^{3}\right)$

Subscripts for kinetic parameters

$d \quad$ dextran

e enzyme

$f \quad$ fructose

$g \quad$ glucose

$i_{d} \quad$ insoluble dextran

$s \quad$ sucrose

$s_{i} \quad$ sucrose at the interface between bulk phase and biofilm

$x \quad$ cell

ye $\quad$ yeast extraction concentration $\left(\mathrm{g} / \mathrm{dm}^{3}\right)$

o initial conditions

\section{References}

Bakke R, Trulear MG, Robinson JA, Characklis WG. 1984. Activity of Pseudomonas aeruginosa in biofilms: steady state. Biotechnol Bioeng 26:1418-1424.

Bird RB, Stewart WE, Lightfoot EN. 1960. Transport phenomena. New York: John Wiley \& Sons. p 45.

Bryers JD. 1984. Biofilm formation and chemostat dynamics: pure and mixed culture considerations. Biotechnol Bioeng 26:948-958.

Chatenever A, Calhoun JC. 1952. Visual examinations of fluid behavior in porous media, I. Trans Am Inst Miner Metal Pet Eng 195:149-156.

Christensen B, Characklis WG. 1990. Physical and chemical properties of biofilms. In: Characklis WG, Marshall KC, editors. Biofilms. New York: Wiley. p 93-130.

Cunningham AB, Characklis WG, Abedeen F, Crawford D. 1991. Influence of biofilm accumulation on porous media hydrodynamics. Environ Sci Technol 25:1305-1311.

Dols M, Remaud-Simeon M, Willemot RM, Demuth B, Jördening HJ, Buchholz K, Monsan P. 1999. Kinetic modeling of oligosaccharide synthesis catalyzed by Leuconostoc mesenteroides NRRL B-1299 dextransucrase. Biotechnol Bioeng 63:308-315.

Donaldson EC. 1991. Microbial enhancement of oil recovery-recent advances. Amsterdam: Elsevier.

Dullien FAL, Dhawan GK. 1974. Characterization of pore structure by a combination of quantitative photomicrography and mercury porosimetry. J Coll Interf Sci 47:337-349.

Fatt L. 1956. The network model of porous media. I, II, III. Pet Trans 207:144.
Hoefner ML, Fogler HS. 1988. Pore evolution and channel formation during flow and reaction in porous media. AIChE J 34:45-54.

Jeanes A, Haynes WC, Wilham CA, Rankin JC, Melvin EH, Austin MJ, Cluskey JE, Fisher BE, Tsuchiya HM, Rist CE. 1954. Characterization and classification of dextran from ninety-six strains of bacteria. J Am Chem Soc 76:5041-5052.

Kim DS, Fogler HS. 1999. The effects of exopolymers on cell morphology and culturability of Leuconostoc mesenteroides during starvation. Appl Microbiol Biotechnol 52:839-844.

Kreikenbohm R, Stephen W. 1985. Application of a two-compartment model to the wall growth of Pelobacter acidigallici under continuous culture conditions. Biotechnol Bioeng 27:296-301.

Lappan RE, Fogler HS. 1994. Leuconostoc mesenteroides growth kinetics with application to bacterial profile modification. Biotechnol Bioeng 43:865-873.

Lappan RE, Fogler HS. 1996. Reduction of porous media permeability from in situ Leuconostoc mesenteroides growth and dextran production. Biotechnol Bioeng 50:6-15.

McKellar M, Wardlaw N. 1982. A method of making two-dimensional glass micromodels of pore systems. J Can Pet Technol 21:39-41.

Peyton BM. 1996. Improved biomass distribution using pulsed injections of electron donor and acceptor. Water Res 30:756-758.

Rege DD, Fogler HS. 1987. Network model for straining dominated particle entrapment in porous media. Chem Eng Sci 42:1553-1564.

Rittmann BE. 1982. The effect of shear stress on biofilm loss rate. Biotechnol Bioeng 24:501-506.

Rittmann BE. 1994. In situ bioremediation, 2nd edition. Park Ridge, NJ: Noyes.

Schiesser WE. 1991. The numerical method of lines. New York: Academic Press.

Tan Y, Gannon JT, Baveye P, Alexander M. 1994. Transport of bacteria in an aquifer sand: experiments and model simulations. Water Res Res 30:3243-3252.

Taylor SW, Jaffé PR. 1990. Biofilm growth and related changes in the physical properties of a porous medium. 1: Experimental investigation. Water Res Res 26:2153-2159.

Taylor SW, Jaffé PR. 1991. Enhanced in-situ biodegradation and aquifer permeability reduction. J Environ Eng 117:25-46.

Vandevivere P, Baveye P. 1992. Effect of bacterial extracellular polymers on the saturated hydraulic conductivity of sand columns. Appl Environ Microbiol 58:1690-1698.

Wardlaw NC. 1976. Pore geometry of carbonate rocks as revealed by pore cases and capillary pressure. AAPG Bull 60:254.

Xiu-Yuan W, Wang XY. 1991. Advances in research, production and application of biopolymers used for EOR in China. In: Donaldson EC, editor. Microbial enhancement of oil recovery-recent advances. Amsterdam: Elsevier. p 467-481. 